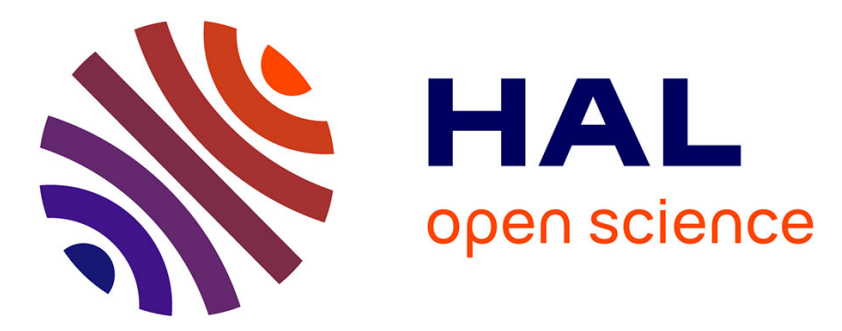

\title{
In situ monitoring of alkanethiol self-assembly onto zinc selenide: the role of substrate pretreatment and its implication in bacterial attachment
}

Elena Yunda, Fabienne Quilès, David Horwat, Raúl Gago, Jaafar Ghanbaja, Halima Alem

\section{To cite this version:}

Elena Yunda, Fabienne Quilès, David Horwat, Raúl Gago, Jaafar Ghanbaja, et al.. In situ monitoring of alkanethiol self-assembly onto zinc selenide: the role of substrate pretreatment and its implication in bacterial attachment. Advanced Materials Interfaces, 2020, 7 (22), pp.2000848. 10.1002/admi.202000848 . hal-03021275

\section{HAL Id: hal-03021275 \\ https://hal.univ-lorraine.fr/hal-03021275}

Submitted on 24 Nov 2020

HAL is a multi-disciplinary open access archive for the deposit and dissemination of scientific research documents, whether they are published or not. The documents may come from teaching and research institutions in France or abroad, or from public or private research centers.
L'archive ouverte pluridisciplinaire HAL, est destinée au dépôt et à la diffusion de documents scientifiques de niveau recherche, publiés ou non, émanant des établissements d'enseignement et de recherche français ou étrangers, des laboratoires publics ou privés. 
Advanced Materials Interfaces, 2020, 7(22), 2000858. DOI:10.1002/admi.202000848

In situ monitoring of alkanethiol self-assembly onto zinc selenide: the role of substrate pretreatment and its implication in bacterial attachment

Elena Yunda, Fabienne Quilès*, David Horwat, Raúl Gago, Jaafar Ghanbaja, and Halima Alem*

Dr E. Yunda, Dr F. Quilès

Université de Lorraine, CNRS, LCPME, F-54000 Nancy, France.

fabienne.quiles@univ-lorraine.fr

Dr E. Yunda, Prof. D. Horwat, Dr J. Ghanbaja, Dr H. Alem

Université de Lorraine, CNRS, IJL, F-54000 Nancy, France.

halima.alem@univ-lorraine.fr

Dr H. Alem

Institut Universitaire de France

Dr R. Gago

Instituto de Ciencia de Materiales de Madrid, Consejo Superior de Investigaciones Científicas, 28049 Madrid, Spain

Keywords: zinc selenide, surface functionalization, alkanethiol self-assembly, infrared spectroscopy, bacterial adhesion

\section{Abstract}

The interface between pioneer sessile bacteria and a supporting substrate can be probed in situ and at the molecular scale by infrared spectroscopy in the attenuated total reflection mode (ATR-FTIR). Here, a self-assembled monolayer (SAM) of amino-terminated alkanethiol is formed on the internal reflection element (IRE) composed of zinc selenide, and the attachment of model bacterium Lactobacillus rhamnosus GG (LGG) is subsequently studied. The impact of the beforehand surface preparation of the IRE on the SAM is studied on ZnSe substrates (i) cleaned by exposure to ozone/UV, (ii) acid cleaned or (iii) coated with a thin gold film. The surface properties of the obtained substrates are analyzed by atomic force and electron microscopies, and elastic ion backscattering spectrometry. The kinetics of the formation and the organization of the formed SAMs are strongly surface dependent, as evidenced with ATR- 
FTIR. Acid-cleaned and gold-coated IREs are the least and most favorable substrates for alkanethiol SAM formation, respectively. Regardless of differences in SAM properties, the average degree of LGG attachment is similar on all functionalized substrates. The molecular organization of LGG cells, however, is substrate-dependent suggesting a possible effect of SAM organization on the bacteria-substrate interface.

\section{Introduction}

Biofilms are defined as communities of microorganisms embedded in a self-produced matrix of extracellular polymeric substances (EPS), and adherent to each other and/or a surface. ${ }^{[1]}$ Biofilms are widespread on biological surfaces in the human body, in the environment, and on surfaces of medical and food equipment, water distribution systems and marine settings. The understanding of the formation of biofilms and, when suitable, the control of this process requires the understanding of the initial stages of their formation - bacterial adhesion. The latter is known to be influenced, among other things, by the surface properties of the support material. ${ }^{[2]}$ In this regard, a large number of methods for detection and monitoring of bacterial adhesion on surfaces has been applied and developed. ${ }^{[3]}$

Among the methods used for the detection and the monitoring of the biofilm formation, infrared spectroscopy in the attenuated total reflection mode (ATR-FTIR) is a powerful tool for the comprehensive investigation of the process of bacterial attachment and early biofilm development (up to $\approx 1-2 \mu$ m thick). This method allows not only detecting biomass increase on the substrate in real time and in situ, but also determining the main biochemical components present in the biofilm without specific sample preparation, e.g. extraction and purification. The possibility to use ATR-FTIR spectroscopy to study sorption of pollutants by biofilms, ${ }^{[4-7]}$ interaction of antimicrobials with biofilms, ${ }^{[8,9]}$ as well as the role of EPS ${ }^{[5,10-13]}$ and support surface ${ }^{[14-17]}$ in biofilm formation has been illustrated. In particular, the works reporting the role 
of support surface on bacterial adhesion were performed using internal reflection elements (IRE) transparent in the infrared and either coated with iron oxides ${ }^{[14,15]}$ or plasma-treated. ${ }^{[16]}$

An advantageous route for surface modification is the self-assembly of alkanethiol molecules. In a simple protocol, this process enables obtaining a well-defined and controlled surface chemistry via covalently attached self-assembled monolayers (SAMs), which functionality can be tuned through the choice of the terminal group of the alkanethiol chain. ${ }^{[18]}$ Indeed, SAMs have been successfully applied in studies of bacterial attachment using, for example, surface plasmon resonance spectroscopy ${ }^{[19,20]}$ and optical microscopy ${ }^{[21]}$ for in situ measurements on functionalized gold. It is noteworthy that SAMs formed on gold surfaces are the most common and well characterized systems for several reasons, including the inertness of gold, facility of the preparation of gold films, the use of gold in many characterization techniques and compatibility of gold with biological samples. ${ }^{[22]}$ Few studies reported the feasibility to form alkanethiol SAMs on the infrared-transparent IRE composed of germanium ${ }^{[23-25]}$ or zinc selenide $(\mathrm{ZnSe}) .{ }^{[17,26]}$ The formation of SAMs on germanium is practically complicated due to the requirement of the surface pretreatment with highly corrosive and toxic hydrofluoric acid to remove surface oxides. ${ }^{[25]}$ Conversely, the surface treatment of $\mathrm{ZnSe}$ can be performed prior to SAM adsorption using less corrosive acidic solutions, e.g. hydrogen peroxide and hydrochloric acid, ${ }^{[27]}$ or by the exposure to ozone combined with UV radiation (ozone/UV). ${ }^{[26]}$ Despite being of interest for ATR-FTIR studies with chemically modified surfaces, the properties of SAMs formed on ZnSe were scarcely addressed in literature $\mathrm{e}^{[17,26]}$.

Here, we decipher the differences in the process of alkanethiol self-assembly onto ZnSe IRE as a function of the surface pretreatment. Three methods to prepare the $\mathrm{ZnSe}$ surface prior to functionalization with the SAM were used: (i) exposure to ozone/UV, (ii) exposure to $\mathrm{H}_{2} \mathrm{O}_{2}$ followed by $\mathrm{HCl}$ aqueous solutions, and (iii) deposition of gold thin film onto $\mathrm{ZnSe}$ followed 
by exposure to ozone/UV. The variations in the surface morphology and composition after these methods of preparation together with their correlation with the kinetics and surface coverage of alkanethiol SAMs are examined in this work. SAMs terminated with the $-\mathrm{NH}_{2}$ functional group were chosen in this study as the amino group provides positive charge on the surface in physiological aqueous media. As most of bacteria are negatively charged in physiological conditions, it is a favorable case for the study of bacterial adhesion on the chemically modified substrate. We then explored the possibility to monitor the first steps of biofilm formation on the functionalized ZnSe using as a model bacterium Lactobacillus rhamnosus GG (LGG). The spectroscopic fingerprints of LGG recorded in situ and in real time revealed that the organization of the molecular groups in bacterial cells was different on gold-coated $\mathrm{ZnSe}$, which could be associated with the highest density of SAM observed on this substrate. The degree of the LGG attachment was similar on $\mathrm{ZnSe}$ functionalized and pretreated by the three methods, indicating the versatility of the applied protocol for $\mathrm{ZnSe}$ surface optimization prior to SAM grafting. Collectively, the results of this study improve the understanding of alkanethiol selfassembly onto ZnSe and advance the potential of infrared spectroscopy in studying bacterial attachment and growth on chemically controlled surfaces.

\section{Results and discussion}

\subsection{Characterization of $\mathrm{ZnSe}$ after surface pretreatments}

Figure 1 shows the atomic force microscopy (AFM) topography images of ZnSe substrates after ozone/UV treatment, $\mathrm{H}_{2} \mathrm{O}_{2} / \mathrm{HCl}$ treatment, and gold coating. The resulting morphology of the substrates is characteristic of each procedure used for the substrate preparation. Long and straight scratches were observed on the surface after ozone/UV treatment (Figure 1a). These scratches are characteristic for $\mathrm{ZnSe}$ after the final polishing step in its manufacturing process ${ }^{[28]}$ and lead to the roughness of the substrate of $\approx 5 \mathrm{~nm}$ (arithmetic average of surface heights measured across a surface, $R_{a}$ ). A drastic change in surface topography was noticed after 
$\mathrm{H}_{2} \mathrm{O}_{2} / \mathrm{HCl}$ treatment. Indeed, the surface showed sphere-like features with the diameter of $\sim 40$ $\mathrm{nm}$, which appeared homogeneously over the crystal surface (Figure 1b). After the acidic treatment, the roughness significantly increased to $\mathrm{R}_{\mathrm{a}} \approx 15 \mathrm{~nm}$. The cross-section of this sample observed by STEM also depicted nanosized hemispheric-like structures ( $50 \mathrm{~nm}$ high $)$ on the surface (Figure 2a). Of interest, these hemisphere-like features had nearly no zinc in their composition, and were very rich in selenium (Figure 2a,b). Thus, the acidic treatment resulted in the preferential dissolution of $\mathrm{Zn}^{2+}$ ions from the surface resulting in a $\mathrm{Se}$ enriched nanostructures on the surface. The enrichment of $\mathrm{ZnSe}$ surface with selenium after $\mathrm{H}_{2} \mathrm{O}_{2} / \mathrm{HCl}$ etching was in accordance with previously reported works on ZnSe etching. ${ }^{[29-31]}$ In the third case, when the ZnSe surface was coated with gold, the morphology reveals a homogeneous granular structure (Figure 1c). The gold grains had the width of $\approx 15 \mathrm{~nm}$, as determined from the AFM measurements. The thickness of the gold coating was determined using ion elastic backscattering spectrometry (EBS) measurements (Figure 3). The area of the Au peak in the EBS spectra corresponds to the atomic areal density, and it was recalculated into the thickness given the known value of gold density. Thus, the equivalent thickness of the Au layer was estimated to be $\approx 2 \mathrm{~nm}$. Similar morphologies of homogeneous few-nanometers thick gold films

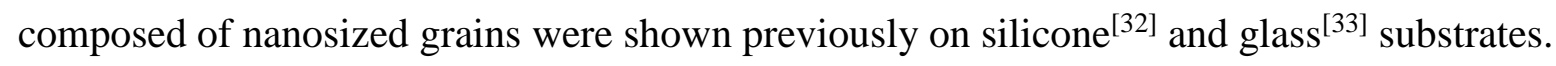

\subsection{Organization of $\mathrm{SAM}$ on $\mathrm{ZnSe}$ and $\mathrm{Au} / \mathrm{ZnSe}$}

Freshly prepared substrates were subjected to a solution of amino-terminated alkanethiol and the kinetics of the self-assembly was monitored in situ by ATR-FTIR spectroscopy (Figure 4). It should be noted that the coating of the ATR crystal with a thin gold film can lead to the enhancement of the intensity of the infrared signal. This effect is called surface enhanced infrared absorption (SEIRA). ${ }^{[34]}$ In this case, the orientation selection rules are those observed in infrared reflection-absorption spectroscopy (IRRAS). Namely, vibrational modes where the change in dipole moment is perpendicular to the surface appear strongly in the spectrum, whereas modes where the change in dipole moment is parallel to the surface appear very weak 
or forbidden. The $v_{\text {asym }} \mathrm{CH}_{2} / v_{\text {sym }} \mathrm{CH}_{2}$ ratios calculated from the spectra of the SAMs on $\mathrm{ZnSe}$ and on $\mathrm{ZnSe}$ coated with gold were not significantly different (data not shown). Moreover, the SEIRA possible signal enhancement was found absent in measurements of phospholipidic supported bilayers onto $\mathrm{Au} / \mathrm{ZnSe}$ with respect to bare $\mathrm{ZnSe}$ (figure $\mathrm{S} 1$ in supporting information). Therefore, we assume that difference in the signal intensity between alkanethiol SAMs on $\mathrm{ZnSe}$ or $\mathrm{Au} / \mathrm{ZnSe}$ arises only from the difference in the surface density of the SAM on these two surfaces, and it is not associated with the possible effects of the thin metal film on the signal intensity. The increase of the integrated intensities of the $\mathrm{vCH}_{2}$ infrared bands on all studied substrates was progressive for the first $\sim 30$ minutes and slowed down after, suggesting a two-stage process (Figure 4a). The mechanism, in which a rapid adsorption of alkanethiol molecules is followed by a slower process of the chain alignment was earlier suggested for SAMs obtained on other substrates. ${ }^{[18,23]}$ In addition, the increase of the intensity of bands as a function of time can be reasoned by a progressive exchange of near-surface solvent with thiol molecules. ${ }^{[35]}$ From the highest value of the integrated intensity of $\nu \mathrm{CH}_{2}$ bands observed for the SAM on $\mathrm{Au} / \mathrm{ZnSe}$ the coverage of the SAM was estimated to be the highest on this substrate. Here, it should be stressed that such result can be not only due to the higher affinity of $\mathrm{S}$ to $\mathrm{Au}$ with respect to $\mathrm{Zn}$ or $\mathrm{Se}$, but also because of a lower roughness of the $\mathrm{Au} / \mathrm{ZnSe}$ substrate that allows a more organized SAM. The low values of the integrated intensities observed on $\mathrm{ZnSe}$ after acidic treatment can thus be associated with the high substrate roughness, but also with the detrimental effect of selenium enrichment at the topmost surface. Indeed, Noble-Luginbuhl and Nuzzo hypothesized that thiols bind preferentially to $\mathrm{Zn}$ on $\mathrm{ZnSe}$ surfaces ${ }^{[26]}$, and the results of the present work are in accordance with this hypothesis.

The experimental values shown in Figure 4a were fitted using equation 1 of Langmuir adsorption and rearrangement model $\left(r^{2} \geq 0.95\right):{ }^{[36]}$ 
$A=A_{0}\left(1-A_{a d s} e^{-t / \tau_{a d s}}-\left(1-A_{a d s}\right) e^{-t / \tau_{r e a}}\right)$,

where $\mathrm{A}_{0}$ is the limiting absorbance of a completely organized monolayer, $\mathrm{A}_{\mathrm{ads}}$ is the adsorption coefficient, $\tau_{\text {ads }}$ is the rate constant of the adsorption phase, and $\tau_{\text {rea }}$ is the rate constant of the slow rearrangement phase. It must be noted that other equations based on Langmuir adsorption model can also be used to fit the kinetics of thiol adsorption. ${ }^{[23,37]}$ Equation 1 was selected owing to its consideration of a slow adsorption phase, unlike other possible models. The results are gathered in Table 1 . The value of $\tau_{\text {ads }}$ obtained on $\mathrm{Au} / \mathrm{ZnSe}$ was $\approx 1.3$ and 1.7 times smaller with respect to $\mathrm{ZnSe}\left(\mathrm{H}_{2} \mathrm{O}_{2} / \mathrm{HCl}\right)$ and $\mathrm{ZnSe}$ (ozone/UV), respectively. Thus, the reaction occurred most rapidly on $\mathrm{Au} / \mathrm{ZnSe}$ and was slower on $\mathrm{ZnSe}$ cleaned with ozone/UV and $\mathrm{H}_{2} \mathrm{O}_{2} / \mathrm{HCl}$. The phase of the slow rearrangement was also affected by the substrate $\left(\tau_{\text {rea }}\right) . \mathrm{On}$ $\mathrm{Au} / \mathrm{ZnSe}$, the arrangement of alkanethiol molecules occurred $\sim 8$ and $\sim 12$ times faster than on $\mathrm{ZnSe}$ treated with ozone/UV and $\mathrm{ZnSe}$ treated with acid, respectively. It can also be noticed that the value of the limiting absorbance $\left(\mathrm{A}_{0}\right)$ was the highest on $\mathrm{Au} / \mathrm{ZnSe}$. The obtained values are overall in the same range as those found in the study of Lacour et al. describing the adsorption of alkanethiols onto gallium arsenide $\left(\mathrm{A}_{\mathrm{ads}}=0.51, \tau_{\mathrm{ads}}=0.11\right.$, and $\left.\tau_{\text {rea }}=2.62\right) .{ }^{[36]}$

The data on the kinetics of SAM formation and surface coverage were in good agreement with the organization of the SAM estimated from the position of $\mathrm{vCH}_{2}$ bands (Figure $4 \mathrm{~b}$ ). Indeed, the lower wavenumber of $v_{\text {asym }} \mathrm{CH}_{2}$ band of the SAM on $\mathrm{Au} / \mathrm{ZnSe}$ compared to $\mathrm{ZnSe}$ suggests a lower number of conformational defects on the former surface. ${ }^{[38]}$ The wavenumbers of $v_{\text {asym }} \mathrm{CH}_{2}$ and $v_{\mathrm{sym}} \mathrm{CH}_{2}$ bands found for the $\mathrm{SAM}$ on $\mathrm{ZnSe}$ in this work were close to those found by Noble-Luginbuhl and Nuzzo for 1-dodecanethiol onto ZnSe, i.e. 2923 and $2853 \mathrm{~cm}^{-1}$, respectively. ${ }^{[26]}$ Based on the results reported in this section, it can be argued that SAM are better organized on $\mathrm{Au} / \mathrm{ZnSe}$ substrates. We evaluate subsequently in the following the influence of the functionalized surface on bacteria attachment. 


\subsection{Attachment of bacteria on functionalized surfaces}

After the functionalization with amino-terminated SAM, ZnSe and Au/ZnSe substrates were subjected to a flow of the bacterial suspension (at optical density 0.5 in physiological saline solution). As the selected SAM was terminated with amine groups, they were protonated under physiological conditions, providing an overall positive charge to the surfaces. ${ }^{[39]}$ Bacteria are characterized with an overall negative charge of their cell wall ${ }^{[40]}$ and hence, they can interact with the functionalized surfaces through electrostatic forces. The attachment of cells was monitored in situ and in real time by ATR-FTIR (Figure 5). The increase of the infrared bands in the spectra suggests the increase of the biomass on all studied surfaces. The bands were characteristic for bacteria, ${ }^{[41,42]}$ showing namely the regions corresponding to proteins $(1590$ $\left.1490 \mathrm{~cm}^{-1}\right)$, nucleic acids and phospholipids $\left(1270-1190 \mathrm{~cm}^{-1}\right)$ and polysaccharides combined with teichoic acids, nucleic acids and phospholipids (1190-956 $\left.\mathrm{cm}^{-1}\right)$. Spectra of LGG were very similar on both $\mathrm{SAM}-\mathrm{NH}_{3}{ }^{+}$made on $\mathrm{ZnSe}$ without the gold coating (Figure 5a,b). Notably, they show the prominent peptido-polysaccharides from the cell wall as they were earlier observed $^{[41]}$ on bare ZnSe (i.e. without a SAM), mostly in region $1070-1000 \mathrm{~cm}^{-1}$. The general feature of the bands absorbing between 1200 and $1000 \mathrm{~cm}^{-1}$ was different on SAM-NH${ }_{3}^{+}$made on the gold-coated ZnSe (Figure 5c). The shoulders between 1070 and $950 \mathrm{~cm}^{-1}$ assigned to polysaccharides were less pronounced. The maximum height was at $1085 \mathrm{~cm}^{-1}$ (mostly assigned to the symmetric stretching of $\mathrm{PO}_{2}$ groups ${ }^{[42]}$ ) and $1080 \mathrm{~cm}^{-1}$ for $\mathrm{LGG}$ on $\mathrm{SAM}-\mathrm{NH}_{3}{ }^{+}$on goldcoated $\mathrm{ZnSe}$ and $\mathrm{SAM}-\mathrm{NH}_{3}{ }^{+}$without the gold coating, respectively. In the case of SAM selfassembled on gold, phosphate groups were then more prominent. Considering these changes in spectral profile, ratios of the integrated intensities of the amide II band (1592-1486 cm $\left.\mathrm{cm}^{-1}\right)$ and bands assigned to polysaccharides and nucleic acids $\left(1189-956 \mathrm{~cm}^{-1}\right)$ were calculated for spectra recorded after $0.5 \mathrm{~h}$ and $2.5 \mathrm{~h}$ of LGG exposure to the surfaces (Table 2). On the surface pretreated by $\mathrm{H}_{2} \mathrm{O}_{2} / \mathrm{HCl}$, all calculated ratios did not vary significantly. On the contrary, ratios 
involving the amide II band were as $\sim 1.3$ lower from $0.5 \mathrm{~h}$ to $2.5 \mathrm{~h}$ of LGG exposure than on the two other prepared SAM-NH${ }_{3}^{+}$(Table 2). These ratios also indicated that the $\mathrm{PO}_{2}$ stretching modes absorbing at $\sim 1230$ and $1085 \mathrm{~cm}^{-1}$ are prominent in the spectra of bacteria attached on these both surfaces. Due to the short time of the experiment, bacteria did not change physiologically. Therefore, the differences between spectra were assigned to the changes in the interactions between the bacteria and the surface. These spectral features could indicate very strong electrostatic interactions of the phosphate groups from teichoic acids (anionic polymers) present at the surface of the Gram-positive bacteria ${ }^{[43]}$ with the high density of $\mathrm{NH}_{3}{ }^{+}$groups on both ozone/UV exposed bare $\mathrm{ZnSe}$ and gold-coated $\mathrm{ZnSe}$ surfaces with respect to the $\mathrm{H}_{2} \mathrm{O}_{2} / \mathrm{HCl}$ prepared surface.

The coverage of the functionalized substrates with LGG was similar on the three substrates, namely $26 \pm 6 \%$ (ZnSe ozone/UV), 36 $\pm 7 \%\left(\mathrm{ZnSe} \mathrm{H}_{2} \mathrm{O}_{2} / \mathrm{HCl}\right)$, and $32 \pm 3 \%(\mathrm{Au} / \mathrm{ZnSe})$ (Figure 5). In fact, the retention of the bacteria after functionalization of $\mathrm{ZnSe}$ (ozone/UV) was 10-fold higher than without the functionalization, which confirms the influence of the functionalization step on the bacterial adhesion force (data not shown). Amide II band is considered as a good indicator of biomass present on the surface in ATR-FTIR spectroscopy. Despite similar bacterial coverages, it can be noticed that amide II band integrated intensities were $0.70,0.82$, and 1.23 for the spectra of LGG exposed to $\mathrm{SAM}_{-} \mathrm{NH}_{3}{ }^{+}$on $\mathrm{HCl} / \mathrm{H}_{2} \mathrm{O}_{2}$, ozone/UV and goldcoated $\mathrm{ZnSe}$ surfaces, respectively. Considering the size of the bacteria $(\sim 2 \mu \mathrm{m} \times 0.8 \mu \mathrm{m})$ and that the SEIRA effect can occur only within $\sim 10 \mathrm{~nm}$ above the surface, ${ }^{[34]}$ the latter phenomenon is negligible here, and thus, cannot explain the higher band intensities on SAM$\mathrm{NH}_{3}{ }^{+}$gold-coated surface. Another parameter affecting the intensity of the bands in ATR-FTIR spectra is the distance between the substrate and the bacterial cells. ${ }^{[44]}$ Indeed, the evanescent wave at the origin of the signal decreases exponentially with the increase of the distance from the surface. Therefore, the higher Amide II band intensity on the gold-coated substrate may be associated with the higher number of $\mathrm{NH}_{3}{ }^{+}$groups (Figure 4a) that lead to a closer contact of 
the bacteria with the substrate, for example, through contracting their outer surface polymers enriched with carboxyl and phosphoryl groups. ${ }^{[4]}$ The result showing similar coverage with bacteria regardless of the substrate indicates, however, that the number of amino groups on $\mathrm{ZnSe}$ without gold coating is still sufficient to maintain the cells attached. Bacteria were homogeneously distributed over the surfaces with a characteristic chain-like pattern, which was especially pronounced on $\mathrm{ZnSe}$ preliminarily treated with ozone/UV and on $\mathrm{Au} / \mathrm{ZnSe}$ surfaces. Such cell-cell organization was previously observed for LGG and other lactobacilli, and is associated with the presence of surface appendages on the cell wall of this bacterium. ${ }^{[17,45-47]}$ LGG cells appeared green after the staining, which suggested the integrity of their membrane, despite the presence of positive charges known as potential bactericides. ${ }^{[48,49]}$ Possibly, this effect was attributed to the fact that LGG, like other Gram-positive bacteria, possess a thick peptidoglycan-rich layer on their cell wall that could act as a protective layer against detrimental electrostatic forces. ${ }^{[49,50]}$

\section{Conclusion}

This study reports the influence of surface pretreatments of $\mathrm{ZnSe}$ IRE on the processes of alkanethiol functionalization and subsequent bacterial attachment. The most drastic change in the morphology and the composition of $\mathrm{ZnSe}$ resulted from the acidic treatment. Indeed, the enrichment of the surface with selenium and the resulting higher roughness led to the lowest degree of functionalization with alkanethiol SAM. In contrast, a well ordered SAM with the highest surface coverage was formed on the gold-coated $\mathrm{ZnSe}$ substrate. On this substrate, the spectroscopic fingerprint of bacterial cells marked the enhanced interaction of the cell wall with the densely present $\mathrm{NH}_{3}{ }^{+}$groups. All functionalized substrates, however, provided sufficient number of positive charges to maintain bacteria attached yet intact. These findings suggest that the three studied pretreatment protocols of $\mathrm{ZnSe}$ prior to alkanethiol functionalization are 
suitable for the study of bacterial attachment, provided a possible impact of the modified IRE surface on bacterial spectral fingerprint is carefully considered.

\section{Experimental Section}

Materials: Trapezoidal ZnSe IREs $(6.8 \mathrm{~cm} \times 1 \mathrm{~cm} \times 0.6 \mathrm{~cm})$ and ZnSe disks $(\varnothing 1.8 \mathrm{~cm}$, thickness $1 \mathrm{~mm}$ ) were purchased from Eurolabo and Crystran, respectively. 11-amino-1undecanthiol hydrochloride (99\%) was purchased from Sigma-Aldrich and used as received for formation of the SAM. Ethanol (RECTAPUR, 99.8\%), isopropanol (SPECTROSOL) were purchased from Carlo Erba. $\mathrm{H}_{2} \mathrm{O}_{2}(30 \%$, AnalaR NORMAPUR) and $\mathrm{HCl}$ (10\% v/v in water) were purchased from VWR and Alpha Aesar, respectively. Sterile ultra-pure water (18.2 M $\Omega$ $\mathrm{cm}$, Elga, Purelab Option-Q) was used to rinse the surface after functionalization of ZnSe with the SAM and after bacterial attachment.

Surface treatment of ZnSe prior to functionalization with the SAM: Prior to functionalization with the SAM, the ZnSe surface was prepared using one of the three methods: (i) exposure to ozone/UV (15 min) followed by the rinse with isopropanol and drying under $\mathrm{N}_{2}$ flow; ${ }^{[26]}$ (ii) dipping of the surface into $\mathrm{H}_{2} \mathrm{O}_{2}(10 \%, 30 \mathrm{~s})$, then into $\mathrm{HCl}(10 \%, 1 \mathrm{~min})(\mathrm{v} / \mathrm{v})$ solutions, and final rinse with ethanol; ${ }^{[27]}$ (iii) coating of ZnSe with gold, by magnetron sputtering as described below, and ozone/UV treatment $(15 \mathrm{~min})$, followed by the rinse with isopropanol and drying with $\mathrm{N}_{2}$ flow. The cleaning and rinsing of the substrates were performed immediately before the mounting of the IRE in the infrared flow cells (Specac) and the start of the functionalization reaction.

Magnetron sputtering of gold onto ZnSe IRE: The deposition of thin films of gold on the surfaces of $\mathrm{ZnSe}$ IRE were performed using direct current magnetron sputtering of a gold target in presence of argon. The crystals were mounted on a rotating holder with the distance of $5 \mathrm{~cm}$ to the gold target (purity 99.99\%). The argon flow in the deposition chamber was $50 \mathrm{~cm}^{3} \mathrm{~min}^{-1}$, whereas the working and base pressure values were $0.4 \mathrm{~Pa}$ and $10^{-4} \mathrm{~Pa}$, respectively. The current applied to the target was $11 \mathrm{~mA}$, resulting in a discharge voltage of $333 \mathrm{~V}$ (Pinnacle Plus DC 
power supply, Advanced Energy). The sample holder was left at floating potential. The samples were etched with argon using radio frequency (RF) supply for 1 minute at $100 \mathrm{~W}$ and superimposed positive bias of $-200 \mathrm{~V}$, which was instantly followed by the deposition of gold for 1 minute. The obtained gold-coated $\mathrm{ZnSe}$ IRE (Au/ZnSe) were stored in ambient air until further use.

Characterization of ZnSe and Au/ZnSe surfaces: The characterization of ZnSe after surface pretreatment was performed on $\mathrm{ZnSe}$ disks. To study morphological features, atomic force microscopy (AFM) images were obtained using an Asylum Research MFP-3D Infinity ${ }^{\mathrm{TM}}$ apparatus equipped with a 100- $\mu$ m close-loop scanner (Santa Barbara, USA). The images were recorded in the contact mode using a silicon nitride probe (MSCT, Bruker). The morphology and composition of $\mathrm{ZnSe}$ surface after treatment with $\mathrm{H}_{2} \mathrm{O}_{2} / \mathrm{HCl}$ was additionally studied using scanning transmission electron microscopy (STEM). A JEM-ARM 200F Cold FEG TEM/STEM instrument operating at $200 \mathrm{kV}$ and equipped with a spherical aberration (Cs) probe was used for STEM analysis of the surface cross-section. This cross-section was prepared using focused ion beam technique (FIB). On the Au/ZnSe sample, the thickness of gold coating was verified using ion elastic backscattering spectrometry (EBS). The EBS measurements were performed with the 5 MV Cockroft-Walton tandetron (HVEE B.V., Amersfoort, The Netherlands) at Centro de Micro-Análisis de Materiales (CMAM) from Universidad Autónoma de Madrid. The incident energy of the $\mathrm{He}^{+}$projectiles was set at $4265 \mathrm{keV}$. As the measurements were performed in parallel with those reported in our previous work, ${ }^{[17]}$ the energy value was selected to enhance the carbon signal at the surface. The incident angle of the beam was $50^{\circ}$, and a scattering angle was set at $170^{\circ}$ for the detection of backscattered ions with a silicon detector. The experimental EBS spectra were analyzed by comparison with simulated spectra in SIMNRA software (Version 7.02). The results presented are representative from four measurements obtained on two different samples (two spots measured on each surface). 
Functionalization of the IRE: The ZnSe trapezoid crystals were enclosed in a flow cell used for infrared spectroscopy as described elsewhere. ${ }^{[17,51]}$ The infrared flow cell with ZnSe or $\mathrm{Au} / \mathrm{ZnSe}$ IRE was filled with $2 \mathrm{mM}$ ethanolic solution of 11-amino-1-undecanthiol hydrochloride and left for self-assembly reaction overnight. The surface of the crystal was subsequently rinsed inside the cell with ethanol and ultra-pure sterile water.

ATR-FTIR in situ monitoring of the SAM adsorption onto ZnSe and Au/ZnSe: A Bruker Tensor 27 FTIR spectrometer equipped with a $\mathrm{KBr}$ beam splitter and a deuterated triglycine sulfate (DTGS) thermal detector was used to record the spectra for monitoring of the self-assembly reaction. The spectrum of ethanol recorded just before the start of each experiment was used as a reference. Nitrogen gas was continuously purged throughout the infrared device for removal of the ethanol vapor, and therefore allowed avoiding its contribution in the infrared spectra. ${ }^{[52]}$ The spectra were recorded every $\approx 1.5$ minutes for the first 45 minutes and then every 20 minutes for a minimum of 15 hours. 100 scans were recorded to obtain each spectrum at a resolution of $4 \mathrm{~cm}^{-1}$. The spectra were processed using OPUS 7.5 software (Bruker, Karlsruhe, Germany). All interferograms were Fourier processed using the Mertz phase correction mode and a Blackman-Harris three-term apodization function. ATR correction was not performed. Water vapor subtraction was performed and baseline was corrected at 3000 and $2820 \mathrm{~cm}^{-1}$. The spectra presented are representative from three independent experiments.

Bacterial strain and culture conditions: Lactobacillus rhamnosus GG (LGG) is a probiotic bacterium, which properties are well described. ${ }^{[53,54]}$ LGG ATCC 53103 strain used in this work was kindly provided by S. Lebeer (University of Antwerp, Belgium). LGG cultures were prepared in accordance with the previously described protocol. ${ }^{[41]}$ Briefly, Man-Rogosa-Sharpe medium (ref. 288130, Difco) was used to prepare subcultures (20 mL, 24 hours) and cultures of bacteria (300 mL, 14 hours). Bacteria were grown in static conditions at $37^{\circ} \mathrm{C}$.

Setup for bacterial attachment experiments: LGG suspensions were prepared from the above culture in $200 \mathrm{~mL}$ of physiological saline solution $(\mathrm{NaCl} 0.9 \%)$ at an optical density of 
$0.50 \pm 0.05$ (cell density meter, model 40, Fisher Scientific, Illkirch, France). These suspensions were pumped around the infrared flow cell as previously described, ${ }^{[41]}$ over the $\mathrm{ZnSe}$ surface functionalized with the SAM. After the flow cell was filled in with the bacterial suspension, the cells were let to adhere onto the crystal for 30 minutes in static conditions. The flow of the bacterial suspension was then carried out for 2 hours at $50 \mathrm{ml} \mathrm{h}^{-1}$ to obtain 2.5 -hours-old biofilms.

ATR-FTIR in situ monitoring of LGG attachment on the functionalized IRE: The spectra were recorded using the same spectrometer as for the monitoring of alkanethiol adsorption, as detailed above. The reference spectrum was recorded immediately after filling in the cell with the bacterial suspension. The spectra were obtained from 100 scans every 10 minutes. Water vapor subtraction was performed and the baseline was corrected at 1800 and $900 \mathrm{~cm}^{-1}$. The experiments were carried out at $21 \pm 1^{\circ} \mathrm{C}$.

Epifluorescence microscopy: The average coverage of the surfaces with bacteria and the integrity of the bacterial membrane were estimated by staining the cells with the BacLight ${ }^{\mathrm{TM}}$ kit (Molecular Probes, ref. L7012). The images were recorded with the $\times 10$ objective of an Olympus BX51 microscope equipped with an Olympus XC50 camera. The BacLight ${ }^{\mathrm{TM}}$ kit contains two dyes, Syto 9 and propidium iodide, which enable determination of the permeability state of the cell membrane. Green-fluorescent Syto 9 is able to penetrate into all cells, whereas red-fluorescent propidium iodide enters only the cells with compromised membranes making damaged bacteria appear red. The IRE with 2.5 -hours-old biofilms were gently rinsed with ultrapure sterile water and bacteria were stained for 20 minutes in the dark at $21 \pm 1^{\circ} \mathrm{C}$. The images $(\approx 60)$ were recorded along the IRE surface, and processed with ImageJ software to calculate the percentage of the coverage of the surface with bacteria.

\section{Supporting Information}

Supporting Information is available from the Wiley Online Library or from the author. 


\section{Acknowledgements}

This work was funded by Carnot Institute ICEEL. The authors are grateful to CC MEM of IJL and especially Sylvie Migot for the FIB preparation of the samples for STEM experiments. We also thank the Spectroscopy and Microscopy Service Facility (SMI) of LCPME (Université de Lorraine-CNRS - http://www.lcpme.cnr-nancy.fr) where infrared experiments were performed.

Received: ((will be filled in by the editorial staff)) Revised: ((will be filled in by the editorial staff))

Published online: ((will be filled in by the editorial staff))

References

[1] H.-C. Flemming, J. Wingender, U. Szewzyk, P. Steinberg, S. A. Rice, S. Kjelleberg, Nature Reviews Microbiology 2016, 14, 563.

[2] H. H. Tuson, D. B. Weibel, Soft Matter 2013, 9, 4368.

[3] G. Schaule, T. Griebe, H.-C. Flemming, in Flemming, H.C., Szewzyk, U., Griebe, T. Biofilms, CRC Press, Boca Raton, 2000.

[4] L. Zhou, F. Dong, H. Li, T. Huo, P. Wang, M. Liu, G. Yang, W. Zhang, W. Hu, X. Nie, H. He, B. Li, R. L. Frost, Chemical Engineering Journal 2019, 359, 393.

[5] S. Kumari, N. Mangwani, S. Das, Spectrochimica Acta Part A: Molecular and Biomolecular Spectroscopy 2017, 173, 655.

[6] J.-H. Huang, E. J. Elzinga, Y. Brechbuehl, A. Voegelin, R. Kretzschmar, Environ. Sci. Technol. 2011, 45, 2804.

[7] J. Schmitt, D. Nivens, D. C. White, H.-C. Flemming, Water Science and Technology 1995, 32, 149.

[8] P. A. Suci, G. G. Geesey, B. J. Tyler, Journal of Microbiological Methods 2001, 46, 193.

[9] F. Quilès, S. Saadi, G. Francius, J. Bacharouche, F. Humbert, Biochimica et Biophysica Acta (BBA) - Biomembranes 2016, 1858, 75.

[10] J. Hou, D. H. Veeregowda, B. van de Belt-Gritter, H. J. Busscher, H. C. van der Mei, Applied and Environmental Microbiology 2018, 84, DOI 10.1128/AEM.01516-17.

[11] D. E. Nivens, D. E. Ohman, J. Williams, M. J. Franklin, J Bacteriol 2001, 183, 1047.

[12] R. M. Donlan, J. A. Piede, C. D. Heyes, L. Sanii, R. Murga, P. Edmonds, I. El-Sayed, M. A. El-Sayed, Applied and Environmental Microbiology 2004, 70, 4980.

[13] G. S. Lorite, A. A. de Souza, D. Neubauer, B. Mizaikoff, C. Kranz, M. A. Cotta, Colloids and Surfaces B: Biointerfaces 2013, 102, 519.

[14] J. J. Ojeda, M. E. Romero-Gonzalez, H. M. Pouran, S. A. Banwart, Mineralogical Magazine 2008, 72, 101.

[15] S. J. Parikh, F. N. D. Mukome, X. Zhang, Colloids and Surfaces B: Biointerfaces 2014, $119,38$.

[16] M. Pousti, J. Greener, Surface Science 2018, 676, 56.

[17] E. Yunda, H. Alem, G. Francius, R. Gago, F. Quilès, ACS Appl. Mater. Interfaces 2020, $12,14933$.

[18] C. D. Bain, E. B. Troughton, Y. T. Tao, J. Evall, G. M. Whitesides, R. G. Nuzzo, J. Am. Chem. Soc. 1989, 111, 321.

[19] J.-S. Guo, P. Zhang, Y.-P. Chen, Y. Shen, X. Hu, P. Yan, J.-X. Yang, F. Fang, C. Li, X. Gao, G.-X. Wang, Chemical Engineering Journal 2015, 279, 516. 
[20] A. Pranzetti, S. Salaün, S. Mieszkin, M. E. Callow, J. A. Callow, J. A. Preece, P. M. Mendes, Advanced Functional Materials 2012, 22, 3672.

[21] K. M. Wiencek, M. Fletcher, Biofouling 1997, 11, 293.

[22] J. C. Love, L. A. Estroff, J. K. Kriebel, R. G. Nuzzo, G. M. Whitesides, Chem. Rev. 2005, 105, 1103.

[23] M. R. Kosuri, R. Cone, Q. Li, S. M. Han, B. C. Bunker, T. M. Mayer, Langmuir 2004, $20,835$.

[24] S. M. Han, W. R. Ashurst, C. Carraro, R. Maboudian, J. Am. Chem. Soc. 2001, 123, 2422.

[25] M. Lommel, E. Mankel, B. Kolbesen, ECS Transactions 2008, 11, 83.

[26] A. R. Noble-Luginbuhl, R. G. Nuzzo, Langmuir 2001, 17, 3937.

[27] C. S. Riccardi, D. W. Hess, B. Mizaikoff, Analyst 2011, 136, 4906.

[28] The Crystran Handbook of Infra-Red and Ultra-Violet Optical Materials, Crystran Ltd, 2016.

[29] T. F. McGee, H. J. Cornelissen, Applied Surface Science 1989, 35, 371.

[30] A. Kita, M. Ozawa, C. D. Gutleben, Applied Surface Science 1996, 100, 652.

[31] J. Zhao, M. H. Na, E. H. Lee, H. C. Chang, J. A. Gardella, H. Luo, Journal of Vacuum Science \& Technology B: Microelectronics and Nanometer Structures Processing, Measurement, and Phenomena 1998, 16, 3048.

[32] A. Klimovskaya, A. Sarikov, Y. Pedchenko, A. Voroshchenko, O. Lytvyn, A. Stadnik, Nanoscale Res Lett 2011, 6, 151.

[33] E. N. Aybeke, Y. Lacroute, C. Elie-Caille, A. Bouhelier, E. Bourillot, E. Lesniewska, Nanotechnology 2015, 26, 245302.

[34] P. R. Griffiths, in Spectroscopic Properties of Inorganic and Organometallic Compounds: Techniques, Materials and Applications, Volume 44, The Royal Society Of Chemistry, 2013, pp. 95-122.

[35] C. Vericat, M. E. Vela, G. Benitez, P. Carro, R. C. Salvarezza, Chem. Soc. Rev. 2010, $39,1805$.

[36] V. Lacour, K. Moumanis, W. M. Hassen, C. Elie-Caille, T. Leblois, J. J. Dubowski, Langmuir 2019, 35, 4415.

[37] S. S. Cheng, D. A. Scherson, C. N. Sukenik, J. Am. Chem. Soc. 1992, 114, 5436.

[38] M. D. Porter, T. B. Bright, D. L. Allara, C. E. D. Chidsey, J. Am. Chem. Soc. 1987, 109, 3559.

[39] K. P. Fears, S. E. Creager, R. A. Latour, Langmuir 2008, 24, 837.

[40] A. T. Poortinga, R. Bos, W. Norde, H. J. Busscher, Surface Science Reports 2002, 47, 1.

[41] E. Yunda, F. Quilès, Biofouling 2019, 35, 494.

[42] B. (Barbara H. ) Stuart, Infrared Spectroscopy : Fundamentals and Applications, Chichester, West Sussex, England; Hoboken, NJ : J. Wiley, [2004] C2004, 2004.

[43] T. Shirashi, S. Yokota, S. Fukiya, A. Yokota, Bioscience of Microbiota, Food and Health 2016, 35, 147.

[44] S.-Y. Kang, P. J. Bremer, K.-W. Kim, A. J. McQuillan, Langmuir 2006, 22, 286.

[45] P. Tripathi, A. Beaussart, G. Andre, T. Rolain, S. Lebeer, J. Vanderleyden, P. Hols, Y. F. Dufrêne, Micron 2012, 43, 1323.

[46] M. Jarosz, J. Grudzień, K. Kamiński, K. Gawlak, K. Wolski, M. Nowakowska, G. D. Sulka, Electrochimica Acta 2019, 296, 999.

[47] M. C. Leccese Terraf, M. S. Juárez Tomás, L. Rault, Y. Le Loir, S. Even, M. E. F. Nader-Macías, Archives of Microbiology 2016, 198, 689.

[48] C. Chen, T. Petterson, J. Illergård, M. Ek, L. Wågberg, Biomacromolecules 2019, 20, 2075.

[49] A. Terada, A. Yuasa, T. Kushimoto, S. Tsuneda, A. Katakai, M. Tamada, Microbiology 2006, 152, 3575 . 
[50] B. Gottenbos, D. W. Grijpma, H. C. van der Mei, J. Feijen, H. J. Busscher, Journal of Antimicrobial Chemotherapy 2001, 48, 7.

[51] A. Delille, F. Quilès, F. Humbert, Applied and Environmental Microbiology 2007, 73, 5782.

[52] E. K. Plyler, Journal of Research of the National Bureau of Standards 1952, 48, Research Paper: 2314.

[53] S. Doron, D. R. Snydman, S. L. Gorbach, Gastroenterol Clin North Am. 2005, 34, 483.

[54] M. E. Segers, S. Lebeer, Microbial Cell Factories 2014, 13, S7. 
Figure 1. AFM topography images of $\mathrm{ZnSe}$ substrates after ozone/UV treatment (a), $\mathrm{H}_{2} \mathrm{O}_{2} / \mathrm{HCl}$ treatment (b), and gold coating (c)
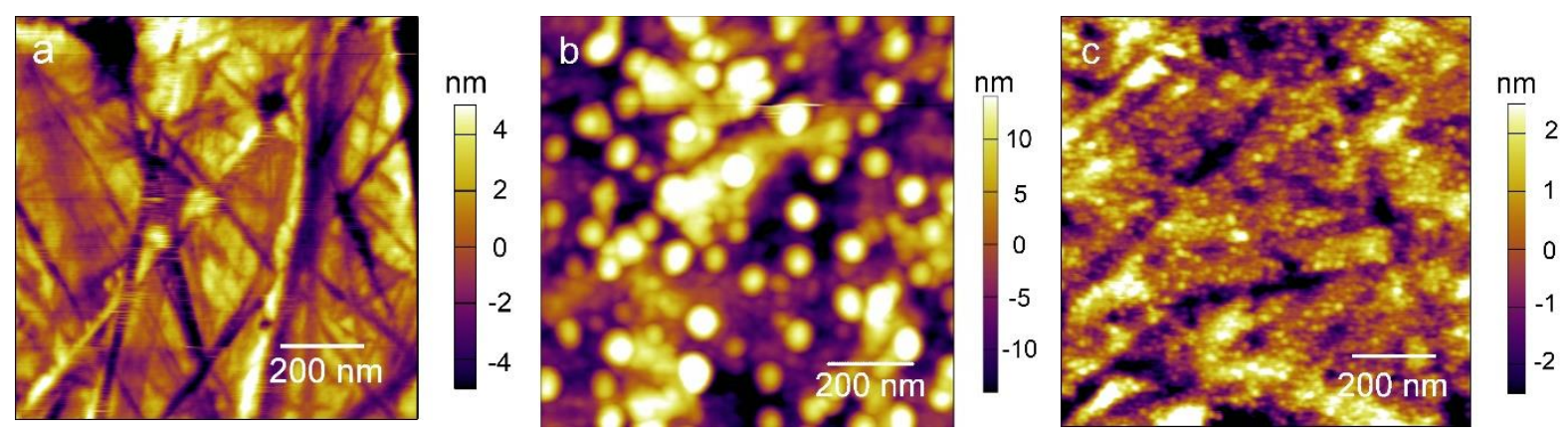

Figure 2. STEM analysis of $\mathrm{ZnSe}$ after $\mathrm{H}_{2} \mathrm{O}_{2} / \mathrm{HCl}$ treatment: SEM photograph of the surface cross-section (a) and EDS maps of the surface cross-section for $\mathrm{Zn}$ (b) and Se (c) elements
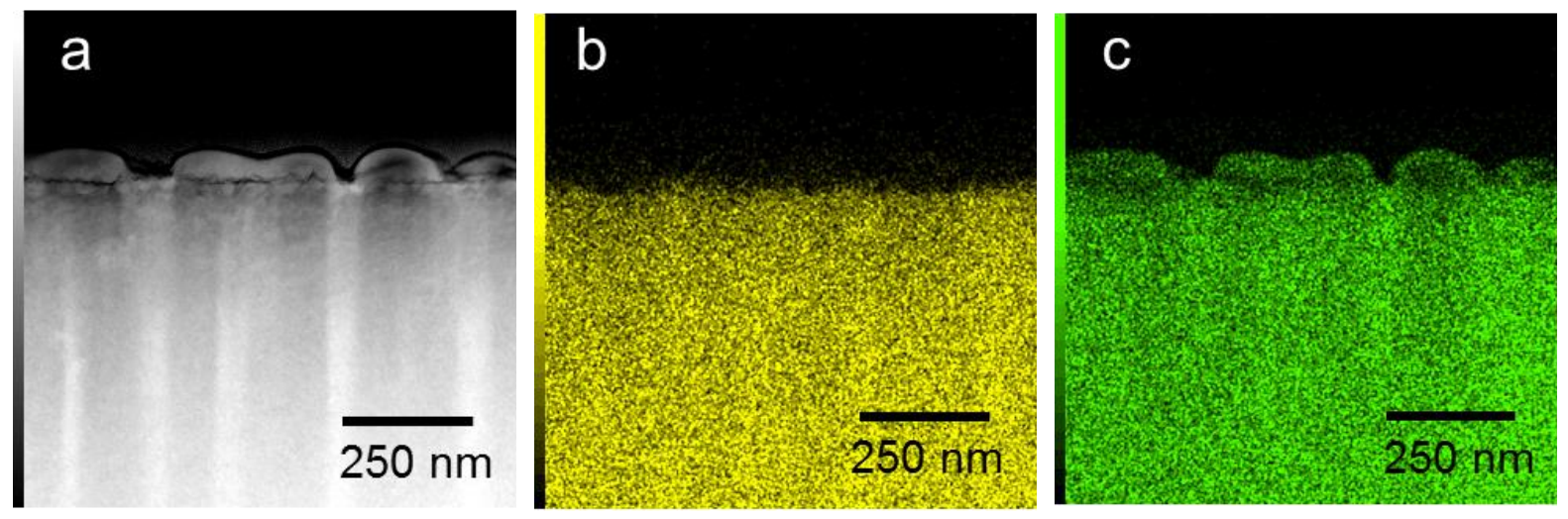

Figure 3. Ion elastic backscattering spectrum showing experimental and simulated curves for the yield of $\mathrm{Zn}$, Se and Au counts on Au-coated $\mathrm{ZnSe}$.

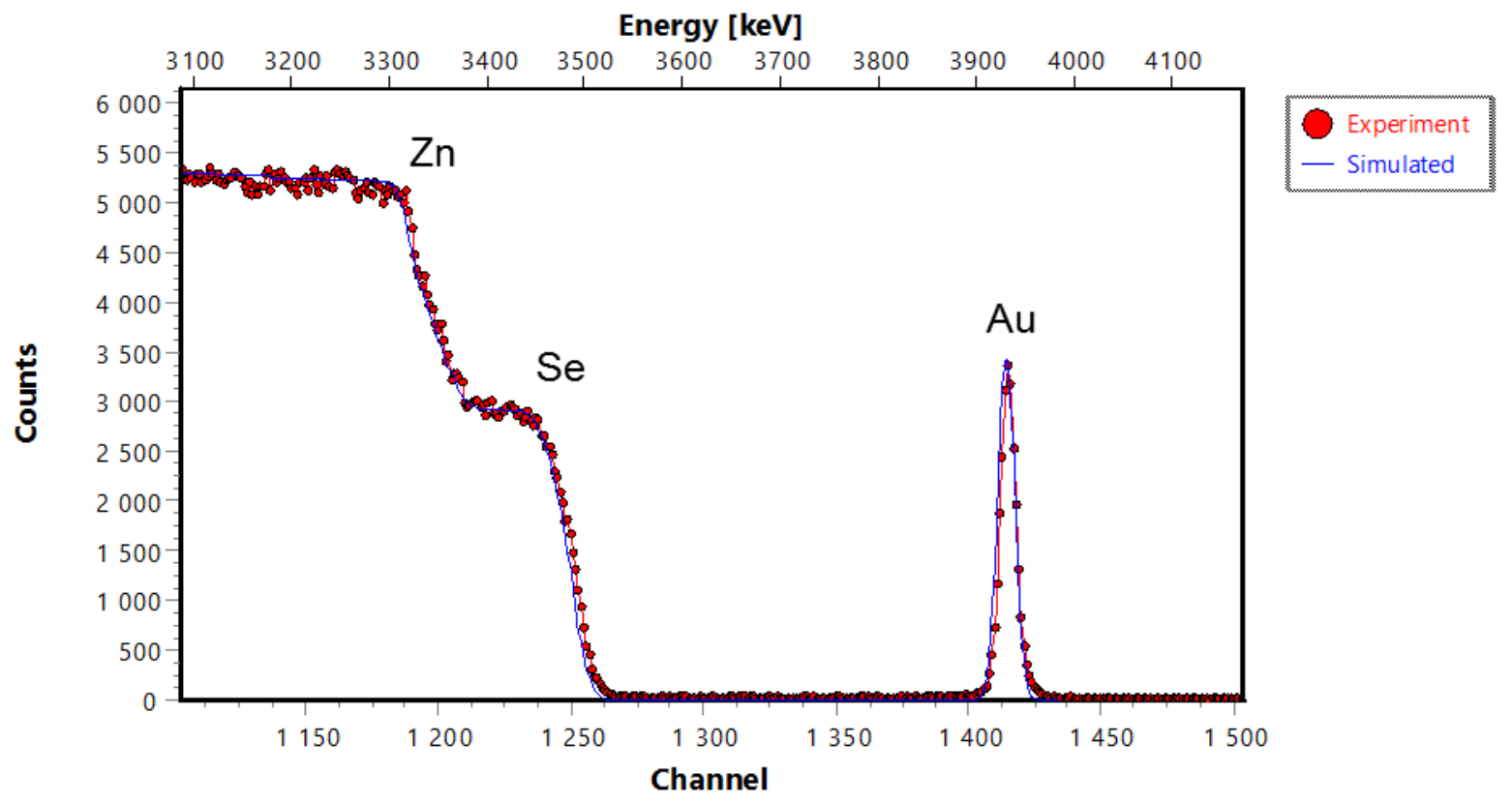


Figure 4. (a) Time evolution of the integrated intensities of $\mathrm{vCH}_{2}$ symmetric and antisymmetric stretching bands (2964-2820 $\mathrm{cm}^{-1}$ ) of amino-terminated alkanethiol adsorbed on the pretreated ZnSe substrates. Standard deviations were obtained from three independent experiments. (b) Corresponding spectra obtained on these substrates after $\sim 2 \min (--)^{-}$and 15 hours (-) of the reaction (the spectrum of ethanol is the reference). The shift of the $\mathrm{vCH}_{2 \text { asym }}$ band to a lower $v$ suggests the increase of ordering in SAMs over time. a.u.: arbitrary units.
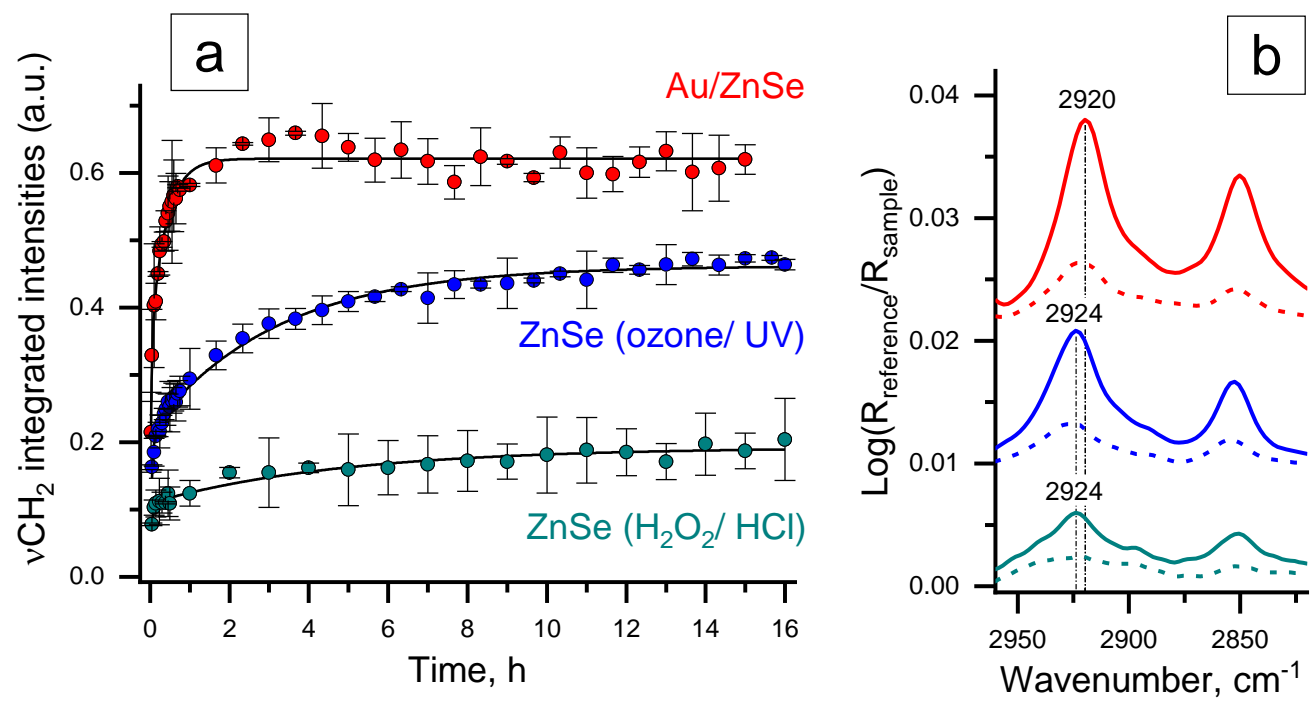
Figure 5. Time-evolution of the infrared spectra in attenuated total reflection mode during the LGG exposure on the substrates functionalized with amino-terminated SAM ((left column, offsets are used for clarity and main assignments are provided), and corresponding epifluorescence images of the bacteria on the substrates after $2.5 \mathrm{~h}$ of exposure (right column, scale bar $-200 \mu \mathrm{m}$ ).

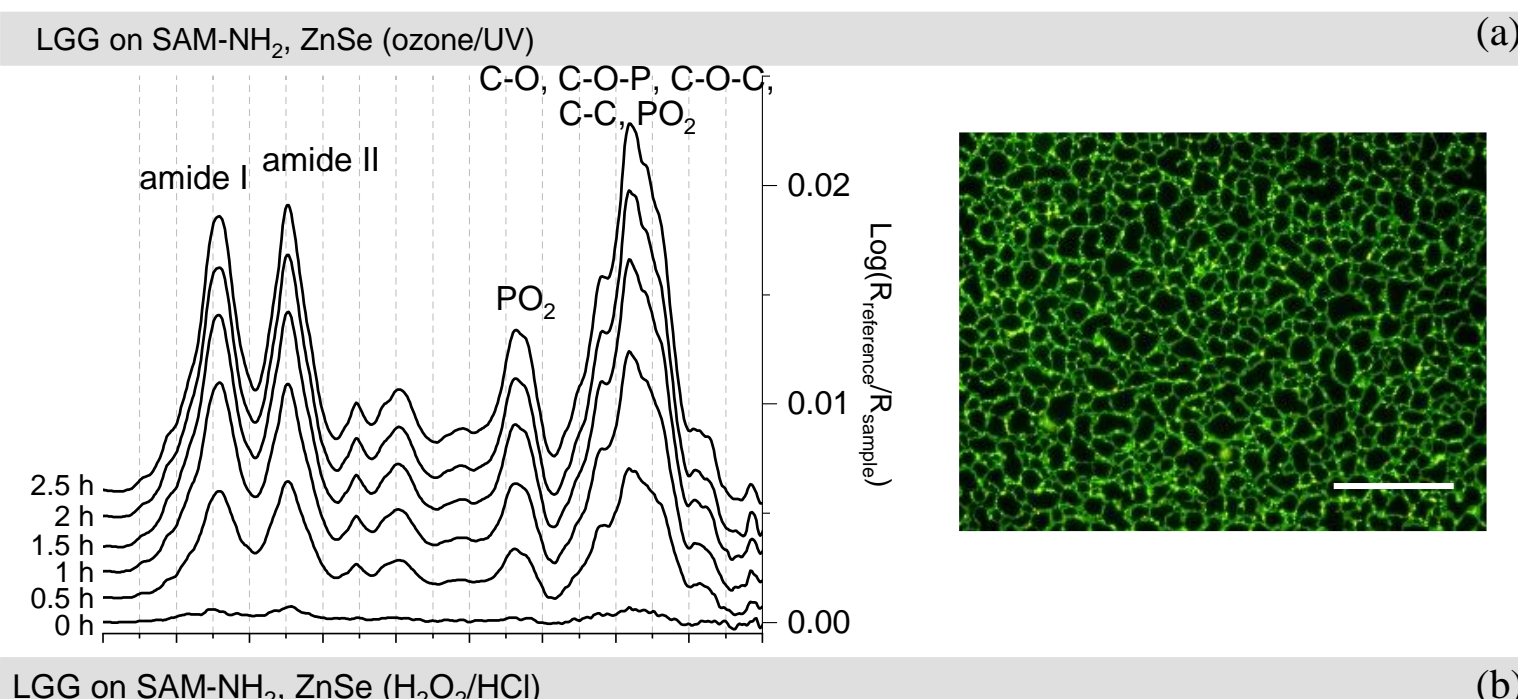

LGG on SAM- $\mathrm{NH}_{2}$, $\mathrm{ZnSe}\left(\mathrm{H}_{2} \mathrm{O}_{2} / \mathrm{HCl}\right)$

(b)
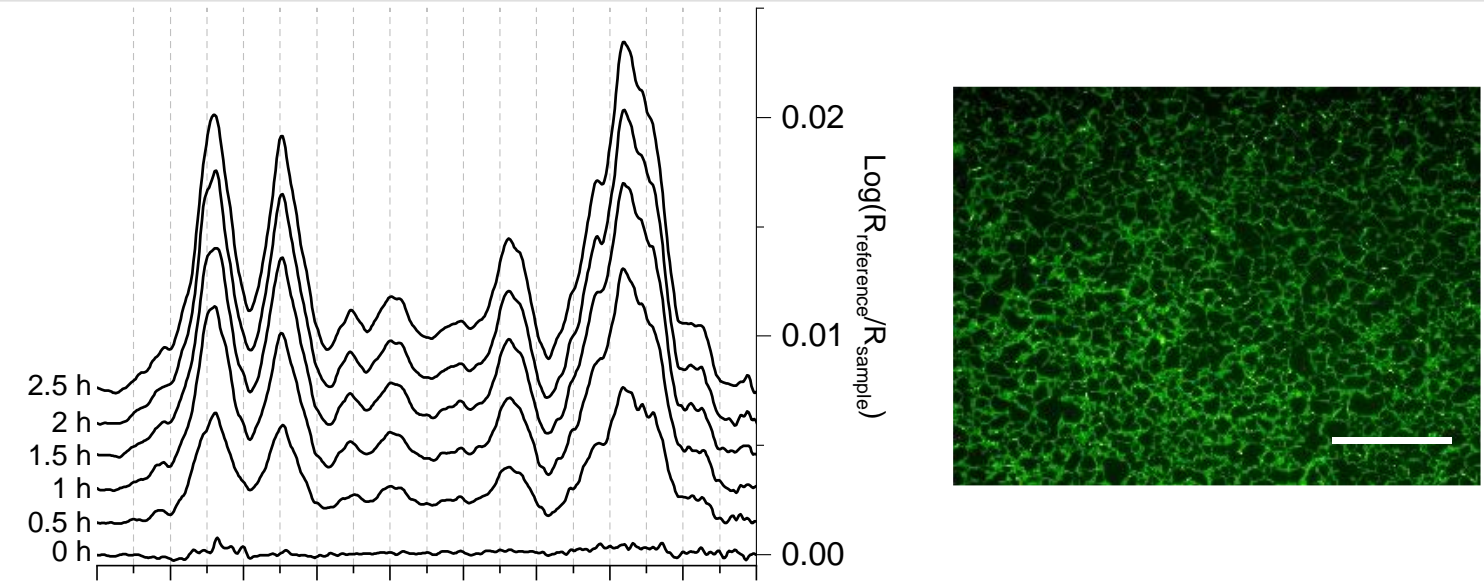

LGG on SAM-NH ${ }_{2}$, Au/ZnSe

(c)
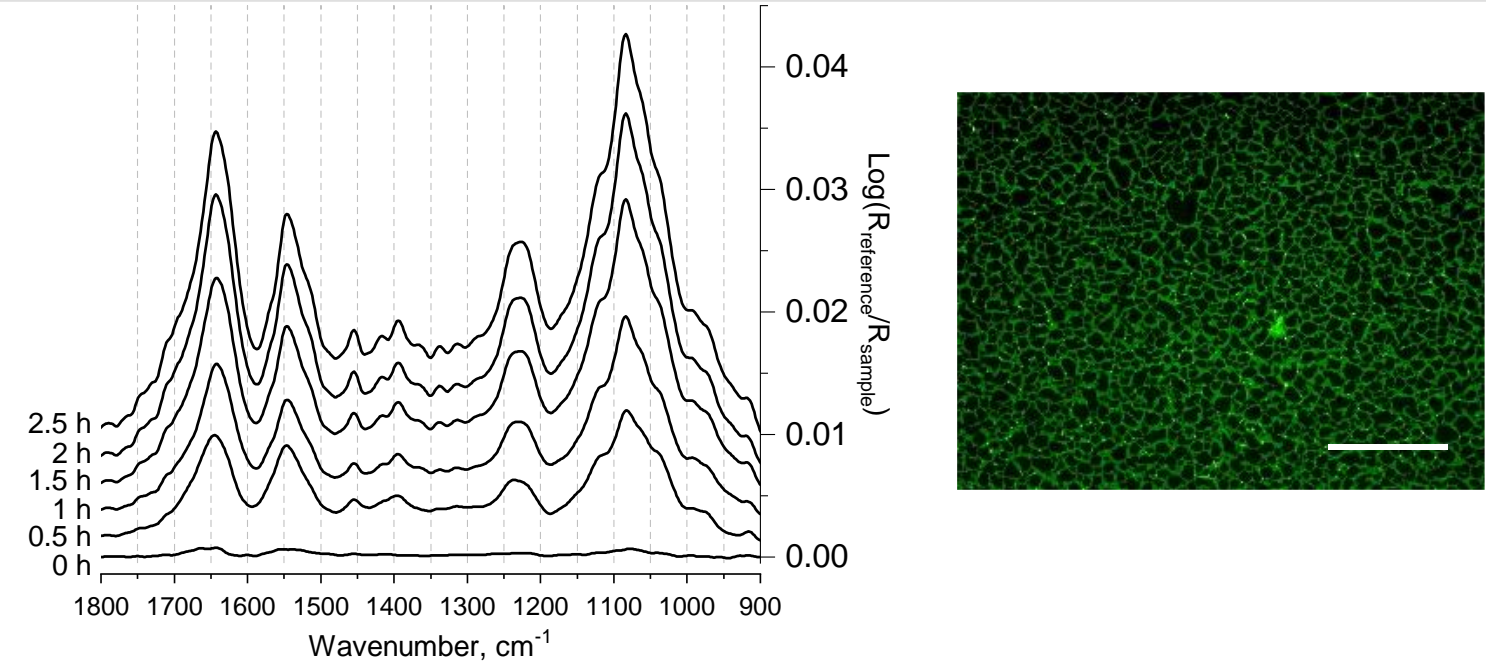
Table 1. Parameters derived from the fitting of adsorption curves of $\mathrm{SAM}-\mathrm{NH}_{2}$ on the three different substrates.

\begin{tabular}{llll}
\hline & Au/ZnSe & $\begin{array}{l}\mathrm{ZnSe} \\
(\text { ozone/UV })\end{array}$ & $\begin{array}{l}\mathrm{ZnSe} \\
\left(\mathrm{H}_{2} \mathrm{O}_{2} / \mathrm{HCl}\right)\end{array}$ \\
\hline $\mathrm{A}_{0}$ & 0.62 & 0.46 & 0.19 \\
$\mathrm{~A}_{\text {ads }}$ & 0.55 & 0.47 & 0.57 \\
$\tau_{\text {ads }}$ & 0.03 & 0.05 & 0.04 \\
$\tau_{\text {rea }}$ & 0.39 & 3.16 & 4.84 \\
\hline
\end{tabular}

Table 2. Ratios of integrated intensities calculated from amide II $\left(1592-1486 \mathrm{~cm}^{-1}\right)$, phosphate antisymmetric stretching $\left(\mathrm{PO}_{2}, 1271-1188 \mathrm{~cm}^{-1}\right)$ and nucleic acids + phospholipids + polysaccharides (NA+PL+PS, $1189-956 \mathrm{~cm}^{-1}$ ) after 0.5 and 2.5 hours of exposure of LGG on the three different substrates.

\begin{tabular}{lllllll}
\hline \multirow{2}{*}{ Pretreatment of the surface for SAM-NH } & \multicolumn{2}{l}{ Amide II/PO } & \multicolumn{2}{l}{ Amide II/AN+PL+PS } & \multicolumn{2}{l}{$\mathrm{PO}_{2} / \mathrm{AN}+\mathrm{PL}+\mathrm{PS}$} \\
\cline { 2 - 7 } & $0.5 \mathrm{~h}$ & $2.5 \mathrm{~h}$ & $0.5 \mathrm{~h}$ & $2.5 \mathrm{~h}$ & $0.5 \mathrm{~h}$ & $2.5 \mathrm{~h}$ \\
\hline $\mathrm{ZnSe}-\mathrm{H}_{2} \mathrm{O}_{2} / \mathrm{HCl}$ & 1.76 & 1.71 & 0.39 & 0.40 & 0.22 & 0.23 \\
$\mathrm{ZnSe}-$ ozone/UV & 2.28 & 1.82 & 0.51 & 0.43 & 0.21 & 0.24 \\
$\mathrm{Au} / \mathrm{ZnSe}$ & 1.64 & 1.18 & 0.42 & 0.31 & 0.25 & 0.26 \\
\hline
\end{tabular}

